\title{
Total Assimilation in Persian Phonology: A Modified Contrastive Specification Account
}

Mohammad.Hajimohammadi ${ }^{1 *}$, Batool.Alinezhad ${ }^{2} \&$ Adel.Rafiei $^{3}$

${ }^{1}$ Ph.D. Candidate in Linguistics at the University of Isfahan, Isfahan, Iran

${ }^{2}$ Associate Professor in Linguistics at the University of Isfahan, Isfahan, Iran

${ }^{3}$ Assistant Professor in Linguistics at the University of Isfahan, Isfahan, Iran

Corresponding Author: Batool.Alinezhad, E-mail: b.alinezhad@fgn.ui.ac.ir

\section{ARTICLE INFORMATION}

Received: August 12, 2020

Accepted: September 30, 2020

Volume: 3

Issue: 9

DOI: $10.32996 / \mathrm{ijl} \mid \mathrm{t} .2020 .3 .9 .26$

\section{KEYWORDS}

Modified Contrastive

Specification Theory, total

assimilation, contrastive

hierarchy, markedness theory.

\section{ABSTRACT}

Nowadays the main stream in the most fields of linguistics including phonology is minimalism and redundancy removing, which derives from the principle of the economy of language. The advent of under specification theory in the late 19th century can be considered as the beginning of redundancy removing in the domain of phonology. During recent decades different versions of under specification such as Radical Under specification, Contrastive Specification and Modified Contrastive Specification (MCS) have been presented. Modified Contrastive Specification (MCS), which is the finding of Toronto Phonology School is based on Contrastive Hypothesis in which a contrastive hierarchy is applied to specify the contrastive features. It is believed that only contrastive features are specified in phonological representations and redundant values never exist in underlying representations. This paper aims to present a novel analysis of total assimilation process in terms of the manner of articulation in consonant clusters having the structures of -st and zd in Persian which is an active process in phonology of Persian. Working within the framework of the MCS, through drawing a contrastive hierarchy for phonological features, this paper leads to this conclusion that the feature [continuant] in Persian consonants is a contrastive feature so by spreading this feature, the coronal stops $/ \mathrm{t} /, / \mathrm{d} /$ assimilate to fricatives $/ \mathrm{s} /$ and $/ \mathrm{z} /$ respectively. To represent contrast and markedness in this system, we have proposed a contrastive hierarchy of [son] > $[\mathrm{lab}]>$ [cont] $>$ [voiced] for consonants involved in the process of total assimilation in Persian.

\section{Introduction}

The concepts of 'markedness' and 'contrast' have been the focus of a large number of research and various proposals have been made concerning their roles in phonological theory (e.g., Saussure, 1916; Sapir, 1925; Trubetzkoy, 1939; Jackobson \& Halle, 1956; Kiparsky, 1982; Pulleyblank, 1986, 1988a, 1988b; Archangeli, 1988; Dresher, Piggott, \& Rice, 1994, 2007; Steriade, 1995; Avery, Dresher, \& Rice 2008; Dresher, 2009).

Rice (2007) believed that the term markedness is used in phonology to capture the fact that not all elements in a phonological system are of equal status. The term markedness was introduced by Trubetzkoy (1939/1969) for the first time in Prague School of phonology to refer to relations between elements of a phonological class (e.g. place of articulation, phonation types) on a language-particular basis. Over the years, the application of this term has grown and expanded in many ways so that today, while the notion of markedness is a core concept to phonological theory, capturing exactly what it means is not straightforward

Jakobson (1941) showed the importance of markedness through dealing with the studies on aphasia, first language acquisition and phonological universals. He believed that the more a phoneme or a feature is marked, the sooner it is lost in language deficit and the latter is acquired in the process of first language acquisition. Chomsky and Halle's approach to

\footnotetext{
K C AL-KINDI CENTER $\mathbf{R}$
$\mathbf{R}$
} Published by Al-KindiCenter for Research and Development. Copyright (c) the author(s). This is an open access article under

CC BY license (https://creativecommons.org/licenses/by/4.0/) 
markedness theory as represented in their major work 'the sound pattern of English' (Chomsky \& Halle, 1968, henceforth SPE) is different, it does not take account of language-particular contrasts, in other words, SPE treats markedness as universal. Dresher (2003) criticizing SPE approach to markedness, emphasized that there is evidence that markedness is relative to particular inventory and it cannot be universal. In Optimality Theory, markedness, which is in the form of a family of constraints, is considered as an essential tool for configuration of phonological generalizations within a language.

Assimilation, among different phonological process, is the most common one occurring in languages over the world, which is related to the both of the above-mentioned concepts, i.e, markedness and contrast. This process has different types in terms of direction, distance and the degree of resemblance between the phonemes undergone the process. It will be discussed in the section devoted to theoretical foundations.

Working within the framework of MCS Theory and structural markedness, this paper aims to analyze the process of total assimilation in the phonology of Persian. The rest of this paper involves literature review, theoretical foundations, data analysis and conclusion respectively.

\section{Former Studies in the Field of MCS Theory}

Dresher and Hall (2009) in a paper entitled 'Contrast in $20^{\text {th }}$ Century and beyond' focused on the specification of contrastive features and contrastive hypothesis. They emphasized that through applying contrastive hierarchy contrastive and marked features are determined and redundant values are omitted from underlying representation.

Dersher (2009) wrote a book entitled 'Contrastive Hierarchy in Phonology' which was the outcome of the research done by him and his colleagues in the university of Toronto. This book is considered as the introduction of "Toronto School of Phonology". The key concepts of the book are 'Contrast' and 'Markedness'. By comparing different approaches to the concepts of contrast and markedness, he argued that the notion of contrast can be understood at several different levels and it has been central to linguistics since Saussure's era.

Hall (2007) in his doctoral dissertations which deals with the role of phonological contrast in determining the featural content of phonological relations, and with the relation between phonological and phonetic contrast emphasized that the 'Successive Division Algorithm (SDA)' is the best tool for reaching contrastive features and removing redundant features.

Rice (2007) extensively investigated the ways for detecting markedness, by focusing on featural markedness which is related to the concept of contrast. She defined two main types of markedness; structural (phonological) markedness and frequency (natural or non-phonological) markedness.

Rohany Rahbar (2009) referring to the research done by Rice (2002) stated that there are different diagnostics to determine the most unspecified feature in a given language. In particular, unmarked elements result from neutralization, are likely to be epenthetic, are the target of assimilation, and are lost in coalescence and deletion. Rohany Rahbar (2012) wrote her doctoral dissertation by the title of 'Aspects of Persian phonology and morpho-phonology' within the framework of MCS theory. As she herself mentioned in her thesis, this work contributes to the field of phonology by arguing that, in the light of the theory of Modified Contrastive Specification, markedness and contrast as defined by this theory, in order to determine the active features of a system, phonological activity in that language should be taken into consideration. This study contributes to our understanding of phonological theory by analyzing the Persian vowel system considering markedness and contrast, concepts of central and current importance and controversy in the theory.

As mentioned above there is just one research on phonological processes concerning the vowels within the framework of MCS theory and no research has been done on the assimilation of the consonants of Persian especially total assimilation. This paper can be considered as the first work in this regard.

\section{Theoretical Foundations}

In this section theoretical framework of this paper is presented. The first part is devoted to the process of assimilation then in the rest of this section under specification theory and its different types specially MCS theory is discussed.

\section{The Process of Assimilation}

When we speak, we do not articulate individual segments separate from each other. Our articulators are always moving from the sound they just made to the sound that is coming up. This means that each speech segment is influenced by the sounds 
that are near it. Before we proceed to the description of different types of assimilation, it seems necessary to determine what assimilation is and how it can be defined. The term assimilation usually refers to contextual variability of speech sounds, which is said to be caused by the influence of one sound upon another. The notion of assimilation presupposes the existence of at least two segments which, by influencing each other, change their phonetic properties. Assimilation is defined as the most common phonological process in which a segment changes to resemble its neighbors more closely (Falk, 1973, p. 126; Roach, 1983, p. 138; Hawkins, 1984, p. 162; Katamba, 1989, p. 36; Ladefoged, 1993, p. 109; Hudson, 2000, p. 113; Gussman, 2002, p. 81; Odden, 2005, p. 228, Ashby \& Maidment, 2005, p. 140)

There are different types of the process of assimilation. Three criteria are used for the classification of assimilation which are as follows:

a. Direction b. Degree of Resemblance c. Distance

According to the criterion of direction, there are two main types of assimilation process;

1. Preservatory assimilation or progressive assimilation

2. Anticipatory assimilation or regressive assimilation

Sometimes the properties of one speech segment persevere into the next segment, in other words, a sound is becoming more similar to the sound that precedes it. This process is called preservatory assimilation or progressive assimilation. Assimilation can go in the other direction too. In anticipatory assimilation or regressive assimilation, a sound is becoming more similar to the sound that follows it. So, assimilation can be anticipatory, where a speech sound is influenced in anticipation of the sound that is about to be spoken after it, or preservatory, where a sound is influenced by properties persevering, or lingering, from the sound that was just spoken.

Based on the criterion of the degree of resemblance, there are two main kinds of assimilation; Partial assimilation and Total assimilation. In partial assimilation the target segment takes on some, but not all, of the characteristics of the source segment. In other words, the resulting assimilant and the assimilator are not identical. By contrast, total assimilation is the limiting case in which the target segment becomes identical to the source segment. In other words, the resulting assimilant becomes identical to the assimilator. This can be expressed by the formula $A B \rightarrow A A$ or $A B \rightarrow B B$.

According to the criterion of distance, there are two main types of assimilation process; contiguous assimilation and distant assimilation. Contiguous (contact) assimilation takes place when there are no intervening segments between assimilee (s) and assimilator (s). And Non-contiguous (distant/ long-distance) assimilation occurs when there are one or more intervening segments between assimilee(s) and assimilator (s).

\section{Underspecification Theory}

The main stream in the most fields of linguistics including phonology is minimalism and redundancy removing, which derives from the principle of language economy. The advent of under specification theory in the late 19th century can be considered as the beginning of redundancy removing in the domain of phonology. This theory focuses on the fact that predictable and redundant information must be deleted from underlying representations. Minimal specification of phonological features was proposed by Jakobson, Martinet and Trobetskov (1952) for the first time. Halle (1962), then, referred to the concept of under specification but the publication of Archangeli's paper entitled 'aspects of Under specification Theory' in 1988 paved the way for writing in this field.

Duanmo (2008) believed that applying under specification results in a more economic phonological analysis and the underspecified phoneme has more transparency so does not block phonological processes. Under pacification theory has been manifested in three versions:

a. Radical Under specification

b. Contrastive Specification

c. Modified Contrastive Specification (MCS)

According to what Archangeli (1988) and Archangeli and Pulleyblank (1989) mentioned, in Radical Under specification, two values are considered for each phonological feature, $(+F)$ means having the feature and $(-F)$ denotes lacking the feature. In this version of Underspacification Theory, only marked values are specified and it is believed that unmarked features are redundant and predictable so must not be specified. 
Avery (1996, p. 49) showed the radical under specification of the feature of [voice] in plosive obstruents and sonorants of English as the following (Table1)

Table 1: Radical Under specification of [voice] in in plosive obstruents and sonorants of English

\begin{tabular}{|l|l|l|l|l|l|l|l|l|l|l|}
\hline & $\mathrm{p}$ & $\mathrm{b}$ & $\mathrm{t}$ & $\mathrm{d}$ & $\mathrm{k}$ & $\mathrm{g}$ & $\mathrm{m}$ & $\mathrm{n}$ & $\mathrm{l}$ & $\mathrm{r}$ \\
\hline [voice] & & + & & + & & + & & & & \\
\hline
\end{tabular}

It is implied that based on Radical Under specification, positive values of the above table denote marked (contrastive) features and unmarked values are absent in underlying representation.

Steriade (1987) and Clements (1988) believed that, in some respects, Contrastive Specification is similar to Radical Underspecification, emphasizing that in Contrastive Specification both values of a feature are specified in underlying representation. Avery (1996, p. 49) showed the contrastive specification of the feature of [voice] in plosive obstruents and sonorants of English (Table 2).

Table 2: Contrastive specification of [voice] in in plosive obstruents and sonorants of English

\begin{tabular}{|l|c|c|c|c|c|c|c|c|c|c|}
\hline & $\mathrm{p}$ & $\mathrm{b}$ & $\mathrm{t}$ & $\mathrm{d}$ & $\mathrm{k}$ & $\mathrm{g}$ & $\mathrm{m}$ & $\mathrm{n}$ & $\mathrm{l}$ & $\mathrm{r}$ \\
\hline [voice] & - & + & - & + & - & + & & & & \\
\hline
\end{tabular}

As illustrated in the above tables ( 1 \& 2), the feature [+voice] is not specified for English sonorants because all of them are voiced and this feature is considered as redundant for them

The third version of Underspecification Theory is known as Modified Contrastive Specification (MCS) theory. Dresher (2003, p. 163) emphasized that MCS theory which is one of the findings of Toronto School of Phonology began with a focus on complexity in phonology and evolved to concentrate on markedness and contrast. MCS has been the subject of a large number of researches including Avery and Rice (1989), Rice and Avery (1989), Dresher (1998a, 1998b, 2003). In the next section, the fundamentals of MCS are presented.

\section{Key Concepts in MCS Theory}

\subsection{Contrast and Contrastive Hierarchy}

Contrast is a basic concept in MCS and as Dresher (2003) expressed has its origin in Saussure's thoughts. Dresher (2009) and Hall (2007) believed that Contrastive Hierarchy is essential for determining contrastive and redundant features. MCS proposes that contrasts are determined by the operation of Successive Division Algorithm, henceforth SDA, on a hierarchy of features. Dresher (2003) emphasizes that analyses of many languages in MCS suggest a certain amount of variation in the feature hierarchy. SDA successively divides the inventory into as many subsets as the feature allows for and keeps dividing up the inventory into sets until every set has only one member. MCS is best characterized with the following principles:

a. Contrastive features must be organized in a hierarchical structure.

b. This hierarchy determines which feature is contrastive in a language.

Hall (2007) analyzes a language having four vowels including $\{i, e, a, u\}$ based on MCS.

The Contrastive Hierarchy proposed by Hall (2007) for this language has been represented in the diagram 1.

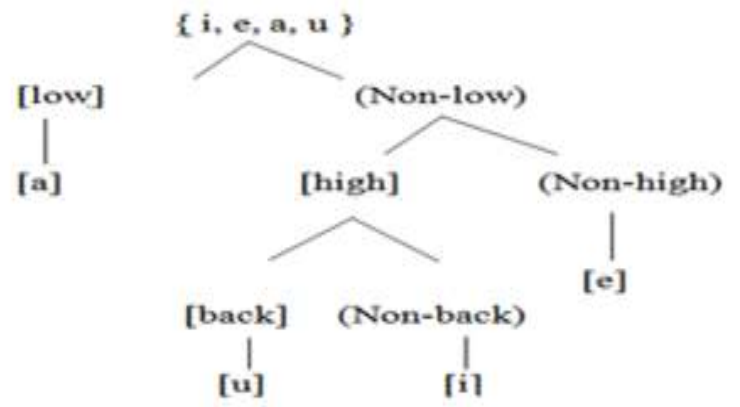

Digram1. Contastive hierarchy for four-vowel system 
This contrastive hierarchy can be represented as [low] $>$ [high] $>$ [back]. As illustrated in the above hierarchy, for [e] no contrastive feature has been specified and [a] has not been specified for the contrastive feature of [back] since it forms a one-member class and according to SDA we must not divide it further.

Based on MCS if the value of a feature is specified by a phonological rule (context-bound or context-free) in the process of derivation, that value is considered as redundant and predictable so it would be absent in underlying representation.

Another important point regarding MCS is this fact that based on the notion of Contrastive hypothesis, in every language, phonological processing operates only on contrastive feature and only contrastive features are phonologically active

\subsection{Monovalent (Privative) vs. Binary (Equipollent) Features}

Phonological features are the formal mechanism used by phonologists to describe speech sounds and explain how they are patterned. Although distinctive (contrastive) features have long been the building blocks of phonology, there is still challenging debates on their basic characteristics. A fundamental debate in feature theory concerns with the fact that how to represent phonological contrasts. Hulst (2016) in the paper entitled 'Monovalent Features in Phonology' emphasized that many phonological distinctions are inherently binary, for instance, segments can be voiced or voiceless, but not half-voiced. Binary contrasts can be expressed in two main ways, which are known as 'equipollent' and 'privative'. The former way assigns a 'label' to each member in the contrast (opposition), while the privative (single-valued) approach assigns a 'label' to only one member, leaving the other literally unmarked:

a. Equipollent: [+voice], [-voice]

b. Privative: [voice], $\varnothing$

An important distinction between binary (equipollent) and unary (privative) approaches in (a) and (b) lies in the fact that the former deals with two values of a feature but the latter does not consider any value (+ or -) for the feature.

In Generative Phonology as Jakobson, Fant and Halle (1952), Chomsky and Halle (1968), Kenstowicz and Kisseberth (1979) mention for each phonological feature two values (+ and -) must be assigned, for instance the contrast between /b/ and /p/ in terms of voicing is represented as [+voice] and [-voice] respectively.

As mentiond earlier, in privative approach which is used in MCS theory, there is no room for positive and negative values and presence and absence of feature are taken into consideration to determine the contrast, in other words, the contrast is between [F] and $\varnothing$. As Carr (1993) stated the member having an extra feature is called marked member and unmarked member is shown with zero. Avery (1996), Dresher, Piggot, and Rice (1994), Lombardi (1991), Hulst (2016), Steriade (1995), and Avery and Idsardi (2001) emphasized that phonological features are unary or privative. Avery and Idsardi (2001) stated that privative approach which assigns zero to unmarked member of the contrast and has been applied in "Revised Autosegmental Phonology" and 'Laryngeal Phonology' has its root in biology and Control Motor Theory. It is believed that based on the fundamentals of MCS, only marked member of the contrast has phonological activity.

\section{Data Analysis}

It is worth nothing that the data used for analysis have been extracted from Iranian native speakers' speech and related books and papers in the field of phonology then the data have been transcribed based on the phonology and phonetics of Persian.

The following Tables (3\&4), present the data for the process of total assimilation in Persian phonology. Table 3 includes total assimilation in the cluster -st and table for comprises of the total assimilation in the cluster-zd.

Table 3: Total assimilation in the cluster -st

\begin{tabular}{llll}
\hline \multicolumn{2}{l}{ The process of Total assimilation } & Gloss \\
daste $\rightarrow$ & [dasse] & The handle \\
peste $\rightarrow$ & [pesse] & The Pistachio \\
baste $\rightarrow$ & [basse] & The package \\
\hline
\end{tabular}


Table 4: Total assimilation in the cluster $-z d$

\begin{tabular}{|c|c|c|c|}
\hline \multicolumn{3}{|c|}{ The process of Total assimilation } & Gloss \\
\hline dozdi & $\rightarrow$ & [dozzi] & The robbery \\
\hline Nazdic & $\rightarrow$ & [nazzic] & Near \\
\hline dozdaci & $\rightarrow$ & [dozzaci] & furtive \\
\hline
\end{tabular}

As already mentioned and illustrated in tables 3 and 4, the process of total assimilation in Persian phonology takes place in consonant clusters -st and -zd. Based on what was mentioned in the section devoted to theoretical foundations, in terms of the direction, total assimilation is a progressive process because the first member of the cluster which is a fricative sound has affected the second member of the cluster, that is, the sound which comes after it.

In terms of the degree of resemblance, this phonological process of Persian is considered as total assimilation because the targeted segment becomes identical to the source segment. In respect of direction this process is called contiguous (contact) assimilation since there is no intervening segments between assimilee and assimilator.

\section{Autosegmental Analysis}

In autosegmetal phonology the following analysis is presented for the total assimilation process.

Suppose that we want to analyze the following case presented in table 3 :

daste $\longrightarrow$ [dasse]

In the above example, the second member of the cluster undergoes the assimilation in terms of manner of articulation and eventually the cluster -st changes to $-\mathrm{ss}$, in fact, /t/ changes to /s/.it can be illustrated as $(/ \mathrm{t} / \rightarrow / \mathrm{s} /)$. In the framework of autosegmental three stages are proposed for representation of the process of total assimilation.

a.Underlying Representation:

Skelet Tier:

Root Tier:

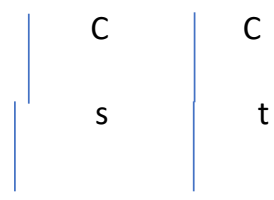

Autosegmental Tier: [+Cont]

[-Cont]

b.Spreading the feature [+Cont] to the target segment and delinking the feature[-Cont]of target segment simultaneously. Skelet Tier:

Root Tier:

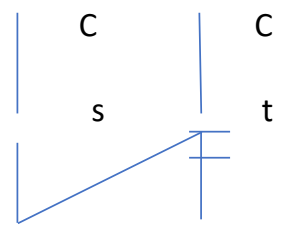

Autosegmental Tier: [+Cont] [-Cont]

c.Surface representation:

Skelet Tier:

C

C

Root Tier:

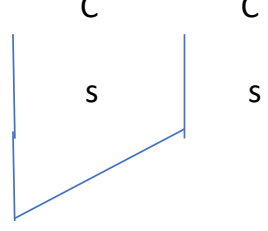

Autosegmental Tier: [+cont] 


\section{Data Analysis within MCS Framework}

As mention earlier MCS applies Contrastive Hierarchy to represent contrastive phonological features, the mechanism used is called SDA in which we successively divide the inventory into as many subsets as the feature allows for and keep dividing up the inventory into sets until every set has only one member. The order of features in Contrastive Hierarchy is so important and varies from one language to another one.

Now we must draw a contrastive hierarchy for the consonants of Persian which are engaged in the process of total assimilation. As already stated, this process occurs in two consonant cluster of Persians which are -st and -zd. For the sake of ease of analysis, a subset of Persian consonants has been selected. This subset includes anterior consonants of Persian which comprises of the following consonants:

$\{/ \mathrm{t} /, / \mathrm{d} /, / \mathrm{s} /, / \mathrm{z} /, / \mathrm{n} /, / \mathrm{m} /, / \mathrm{l} /, / \mathrm{r} /, / \mathrm{p} /, / \mathrm{b} /, / \mathrm{f} /, / \mathrm{v} /\}$

All of the above consonants possess the feature of [anterior]. The first cut in our contrastive hierarchy which results in binary division, separates anteriors having the feature [sonorant] from non-sonorant anteriors:

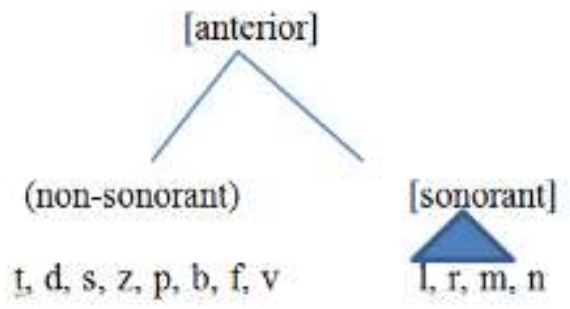

Digram 2. anteriors having the feature [sonorant] from non-sonorant anteriors

According to the procedure used in contrastive hierarchies, we draw a triangle for segments not engaged in the process under consideration.

The result of the first cut done by SDA is the separation of sonorant anteriors of Persian from obstruent (non-sonorant) anteriors. The second cut is done by the contrastive feature [labial] which divides the set of obstruent (non-sonorant) anteriors into two subsets; labial obstruent anteriors and non-labial obstruent anteriors which are represented in the following hierarchical structure:

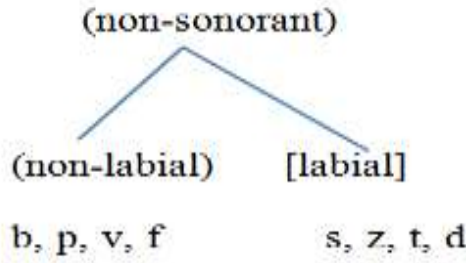

Digram 3. Labial obstruent anteriors and non-labial obstruent anteriors

The third stage involves dividing the above sets into two subsets by using the contrastive feature [continuant]. The result has been shown in the following hierarchical structures:
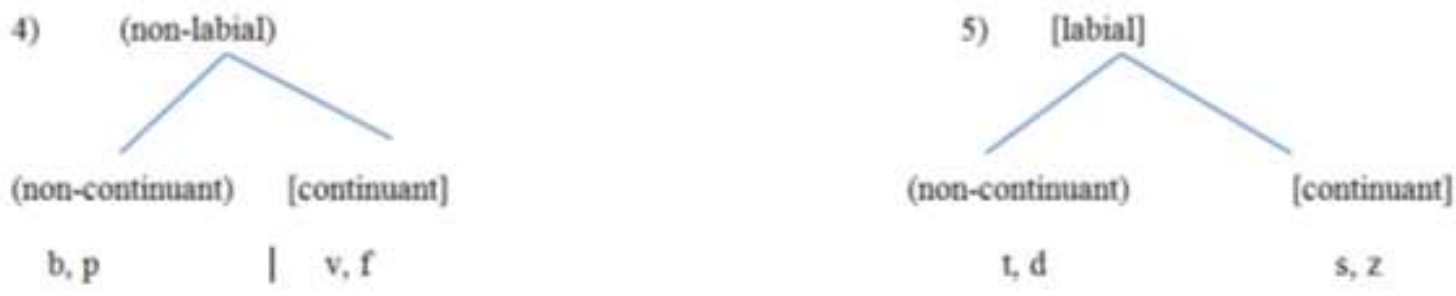

Digram 4 \& 5. Non-labial and labial hierarchical structures 
According to the procedure of SDA which has already mentioned in the section devoted to theoretical foundations, SDA successively divides the inventory into as many subsets as the feature allows for and keeps dividing up the inventory into sets until every set has only one member.

To reach one member in terminal nodes we need another contrastive feature which is [voiced]. The final version of the contrastive hierarchy used to represent total assimilation in Persian phonology is as follows:

\section{t, d, s, z, p, b, f, v, 1, r, m, n}

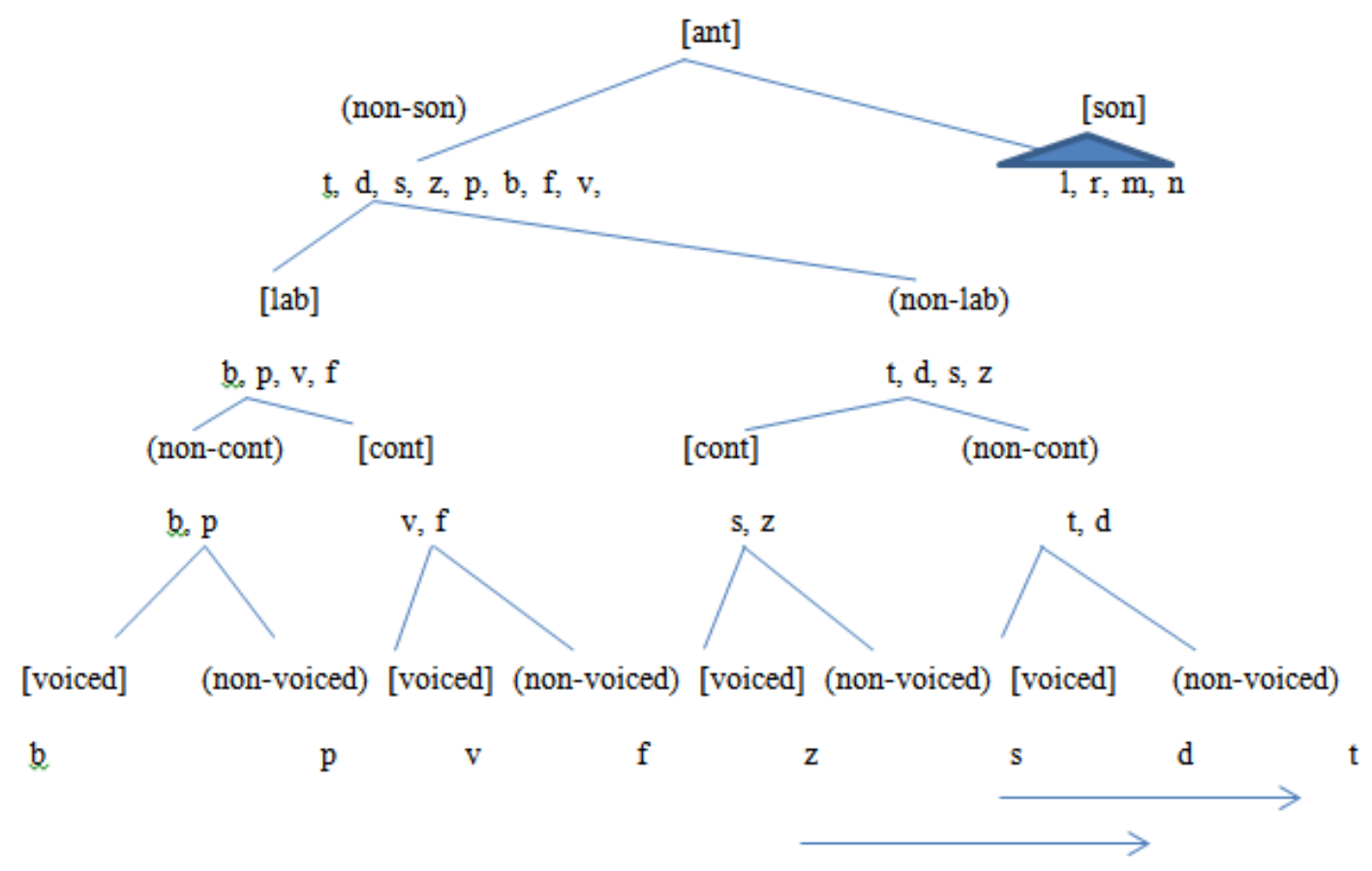

Digram 6. The final version of the contrastive hierarchy of total assimilation in Persian phonology

The above contrastive hierarchy can also be shown as the following:

$[$ Son $]>[$ lab] $>$ [cont $]>[$ voiced $]$

As illustrated in the diagram 6 , both of the phonemes $/ \mathrm{s} /$ and $/ \mathrm{t} /$ are common in lacking the contrastive features [voiced] , [labial] and [sonorant] and their only difference is in terms of the contrastive feature [continuant] that has been specified for $\mathrm{s} /$ and has not been specified for $/ \mathrm{t} /$. By spreading this feature from $/ \mathrm{s} /$ to $/ \mathrm{t} /$, total assimilation takes place and two segments become identical, the arrow shows the direction of the change.

According to the above contrastive hierarchy (diagram6), the phonemes / $/$ / and / $d$ / are identical in all characteristics except the contrastive feature [continuant]. The contrastive feature [continuant] that has been specified for $/ \mathrm{z} / \mathrm{but}$ has not been specified for /d/. Just like the above case, by spreading this feature from $/ \mathrm{s} /$ to $/ \mathrm{t} /$, total assimilation occurs and two phonemes become identical in all aspects, the arrow shows the direction of the change.

In sum, through total assimilation, the contrastive feature [continuant] spreads from fricative consonants, i.e, $/ \mathrm{s} / \mathrm{and} / \mathrm{z} /$ to unmarked coronal consonants, i.e, /t/ and /d/ respectively.

Baesd on the above contrastive hierarchy (diagram 6) feature specification for the phonemes involved in the process of total assimilation has been shown in the Table 5 below. 
Table 5: Feature specification for phonemes involved in the process of total assimilation

\begin{tabular}{lccc}
\hline Phoneme & [labial] & [continuant] & [voiced] \\
\hline$/ \mathrm{s} /$ & $\checkmark$ & $\checkmark$ \\
\hline $\mathrm{z} / \mathrm{Feature}$ & & $\checkmark$ & $\checkmark$ \\
\hline $\mathrm{d} / \mathrm{t} / \mathrm{V}$ & & \\
\hline
\end{tabular}

As illustrated in Table 5, the contrastive feature [continuant] has been specified for fricative consonants $/ \mathrm{s} /$ and $/ \mathrm{z} /$ and has not been specified for coronal consonants $/ \mathrm{d} /$ and $/ \mathrm{t} /$, so fricatives $/ \mathrm{s} /$ and $/ \mathrm{z} /$ play the role of the triggers in the process of assimilation and coronals $/ \mathrm{d} /$ and $/ \mathrm{t} /$ take the role of the targets of assimilation.

According to the principles of structural (phonological) markedness proposed by Rice (2007), marked segments are determined as the trigger of the process of assimilation and unmarked segments are considered as the target of the process of assimilation so it is concluded that the fricative consonants $/ \mathrm{s} /$ and $/ \mathrm{z} /$ are marked segments and coronal consonants /d/ and / $\mathrm{t} /$ are unmarked ones.

The least marked consonant among the above consonants is the coronal consonant /t/ which has no contrastive feature so easily undergoes the process of total assimilation another target of total assimilation is the coronal consonant /s/ which has not been specified in terms of being continuant.

Additionally, Paradis and Prunet (1989) emphasized that in a large number of languages all over the world coronals are considered as unmarked segments which simply undergo the phonological processes. As it is clear, the result of this paper conforms to the finding of Rice (2007) and Paradis and Prunet (1989).

\section{Conclusion}

The general tendency for minimalism and redundancy removing is a main stream in different fields of linguistics including phonology. As already mentioned, the underspecification theory is considered as the pioneer of this stream in phonology. Working within the framework of the MCS, through drawing a contrastive hierarchy for the segments involved in the process of total assimilation, we argued in this paper that in this process occurring in the clusters -st and -zd in Persian which is a contiguous and progressive assimilation, the contrastive feature [continuant] spreads from the fricatives $/ \mathrm{s} /$ and $/ \mathrm{z} /$ to the coronals / $\mathrm{t} /$ and /d/ respectively and eventually two members of the cluster become identical in all respects. The result obtained in this paper is in accordance with the previous researches emphasizing on the unmarked status of coronals.

\section{References}

[1] Ashby, M., \& Maidment, J. (2005). Introducing Phonetic Science. Cambridge: Cambridge University Press.

[2] Archangeli, D. (1984). Underspecification in Yawelmani Phonology and Morphology. Doctoral dissertation, Massachusetts Institute of Technology.

[3] Archangeli, D. (1988). Aspects of underspecification theory. Phonology, 5, 183-207.

[4] Archangeli, D., \& Pulleyblank. D. (1989). Yoruba Vowel Harmony. Linguistic Inquiry, 20, 173-218.

[5] Avery, J.P. (1996). The Representation of Voicing Contrasts. Doctoral dissertation University of Toronto.

[6] Avery, J. P., \& Rice, K. D.(1989). Segment Structure and Coronal Underspecification. Phonology, 6 (2), 179-20.

[7] Avery, J. P., Dresher, B. E., \& Rice, K. (2008). Contrast in Phonology: Theory, Perception, Acquisition. Berlin: Mouton de Gruyter

[8] Chomsky, N., \& Halle, M.(1968). The Sound Pattern of English. New York: Harper and Row.

[9] Clements, G. N. (1991). Vowel Height Assimilation in Bantu Languages. Working Papers of Cornell Phonetics Lab, 5, 37-76.

[10] Dresher, B. E. (1998a). Contrast in Inventories. Presented at the Montr'eal-Ottawa Toronto Phonology Workshop, University of Ottawa.

[11] Dresher, B. E. (1998b). On Contrast and Redundancy. Presented to the Canadian Linguistic Association, University of Ottawa.

[12] Dresher, B. E. (2003). The Contrastive Hierarchy in Phonology. Toronto Working Papers in Linguistics, $20,47-62$.

[13] Dresher, B. E. (2009). The contrastive hierarchy in phonology. Cambridge University Press, Cambridge.

[14] Falk, J.S. (1973). Linguistics and Language. New York: John Wiley \& Sons.

[15] Goldsmith, J. A. (1976). Autosegmental phonology. MIT PhD dissertation (published 1979), New York: Garland.

[16] Gussmann, E. (2002). Phonology, Analysis and Theory, Cambridge: Cambridge University Press.

[17] Jakobson, R., Fant, G., \& Halle M. (1952). Preliminaries to Speech Analysis. Technical Report 13, MIT Acoustics Laboratory.

[18] Duanmo, S. (2008). The Syllable Structure: The limits of variation. Oxford: Oxford University Press. 
[19] Ghomeshi, J. (1996). Projection and Inflection: A study of Persian phrase structure. PhD dissertation. Toronto Working Papers in Linguistics.

[20] Hall, D. C. (2007). The Role and Representation of Contrast in Phonological Theory. Doctoral dissertation, University of Toronto.

[21] Halle, M. (1962). Phonology in generative Grammar. Word, 18, 54-72.

[22] Hawkins, P. (1984). Introducing Phonology. London: Routledge.

[23] Hudson, G. (2000). Essential Introductory Linguistics. Oxford: Blackwell.

[24] Hulst, H. V. (2016). "Monovalent features in phonology". Language and linguistic compass.10/2, 83-102.

[25] Katamba, F. (1989). An Introduction to Phonology. London and New York: Longman.

[26] Kiparsky, P. (1985). Some consequences of lexical phonology. Phonology Yearbook, 2, 83-138.

[27] Ladefoged, P. (1993). A Course in Phonetics (3 ${ }^{\text {rd }}$ ed.). Sydney: Harcourt Brace,College Publishers.

[28] Lazard, G. (1992). A Grammar of contemporary Persian. Mazda, Costa Mesa, California. Translated from French by Shirley Lyons.

[29] Lewis, M. P. (2009). Ethnologue: Languages of the World, $16^{\text {th }}$ ed. Dallas, Tex: SIL International.

[30] McCarthy, J.J. (1988). Feature geometry and dependency: A review. Phonetica, 43-61.

[31] Odden, D. (2005). Introducing Phonology. Cambridge: Cambridge University Press.

[32] Paradis, C., \& Prunet, J. F. (1989). On Coronal Transparency. Phonology, 6, 317-348.

[33] Rice, K. D., Avery, J. P. (1989). On the Interaction between Sonorancy and Voicing. Toronto Working Papers in Linguistics, $10,65-82$.

[34] Rice, K. (2007). Markedness in phonology. In The Cambridge handbook of phonology, pp: 79-97. Cambridge University Press.

[35] Roach, P.(1983). English Phonetics and Phonology. Cambridge: Cambridge University Press.

[36] Rohany Rahbar, E. (2009). Coronal vowels in Persian. Toronto Working Papers in Linguistics 30, 119-129.

[37] Rohany Rahbar, E. (2012). Aspects of Persian phonology and morpho-phonology. Ph.D. thesis. University of Toronto.

[38] Sapir, E. (1925). Sound Patterns in Language. Language, 1, 37-51.

[39] Saussure, F. D. (1916). Cours de linguistique g'en'erale. Paris: Payot.

[40] Steriade, D. (1987). Locality conditions and feature geometry. In proceeding of NELS 17, Amherst: GLSA, University of Massachusetts, 595-618.

[41] Steriade, D. (1995). Underspecification and Markedness. In The handbook of phonological theory, Oxford: Basil Blackwell. 74-114.

[42] Trask, R. L. (1996). Historical Linguistics. Arnold: London.

[43] Trubetzkoy, N. S. (1939). Grundzüge der Phonologie. Prague: Cercle Linguistique de Prague. Translated 1969 as Principles of Phonology by Christine A. M. Baltaxe. Berkeley and Los Angeles: University of California Press. 